\title{
Shape Memory Behavior of Rapidly Quenched High- copper TiNiCu Alloys
}

\begin{abstract}
Alexander Shelyakov ${ }^{1}$, Nikolay Sitnikov ${ }^{2}$, Irina Khabibullina ${ }^{3}$, Kirill Borodako ${ }^{4}$, Oleg Sevryukov ${ }^{5}$

${ }^{1}$ National Research Nuclear University MEPhI (Moscow Engineering Physics Institute), Kashirskoe shosse 31, 115409 Moscow, Russia (alex-shel@mail.ru) ORCID 0000-0002-26036648; ${ }^{2}$ National Research Nuclear University MEPhI (Moscow Engineering Physics Institute), Kashirskoe shosse 31, 115409 Moscow, Russia; Federal State Unitary Enterprise Keldysh Research Center, Onezhskaya St. 8, 125438 Moscow, Russia (sitnikov_nikolay@mail.ru) ORCID 0000-0002-2786-914X; ${ }^{3}$ National Research Nuclear University MEPhl (Moscow Engineering Physics Institute), Kashirskoe shosse 31, 115409 Moscow, Russia; Federal State Unitary Enterprise Keldysh Research Center, Onezhskaya St. 8, 125438 Moscow, Russia (irinazaletova@mail.ru); ${ }^{4}$ National Research Nuclear University MEPhl (Moscow Engineering Physics Institute), Kashirskoe shosse 31, 115409 Moscow, Russia (borodako_kir@mail.ru); ${ }^{5}$ National Research Nuclear University MEPhI (Moscow Engineering Physics Institute), Kashirskoe shosse 31, 115409 Moscow, Russia (sevr54@mail.ru)
\end{abstract}

\begin{abstract}
Rapidly quenched quasibinary $\mathrm{TiNi}-\mathrm{TiCu}$ system alloys with high copper contents (above 20 at.\%) exhibit excellent shape memory effect and have considerably narrower hysteresis as compared with the TiNi binary alloy, this advantage being of special importance for cyclic load applications, e.g. for microelectromechanics (MEMS). The aim of this work is to study the effect of annealing parameters and copper content on the shape memory effect in TiNiCu alloys. Thin amorphous ribbons of TiNi-TiCu alloys with copper contents of 25 to 40 at.\% were produced by planar flow casting at a melt cooling rate of about $106 \mathrm{~K} / \mathrm{s}$. The alloys were crystallized by isothermal annealing with variable duration and by exposing specimens to a short (10 ms) electric pulse. Increasing the copper content to above 30 at.\% considerably reduces the plasticity and shape memory effect of the alloys. However, significant reduction of annealing duration greatly improves the shape memory performance due to prevention of the formation of brittle Ti-Cu phases in the alloys structure.
\end{abstract}

Author Keywords. Shape Memory Alloys, Rapid Quenching of Melt, Amorphous State, Electropulse Treatment, Martensitic Transformation, Shape Memory Effect.

Type: Research Article

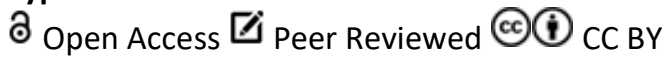

\section{Introduction}

Thanks to their unique properties, shape memory effect (SME) alloys are considered as efficient and promising materials for aeronautic and space industries, biomedicine, robotics and MEMS (Kohl et al. 2018; Otsuka and Ren 2005; Mohd Jani et al. 2014). TiNi alloys of close to equiatomic compositions have found the broadest application but the relatively wide thermal hysteresis (approx. $30^{\circ} \mathrm{C}$ ) of their martensitic transformation (MT) precludes further expansion of their applications in fast-response actuators.

Nickel replacement for copper (in an amount of above 10 at.\%) in the binary TiNi alloy leads to a transformation from the cubic austenite phase B2 to the orthorhombic martensite phase B19 having narrow hysteresis whose width decreases with an increase in copper content (Kang et al. 2010; Chang, Wu, and Kimura 2007; Nam, Saburi, and Shimizu 1990). Thin ribbons made 
of quasibinary TiNi-TiCu system alloys by means of rapid quenching from the melt are an attractive material for the fabrication of microactuators (Nespoli et al. 2010) due to their narrow thermal hysteresis, relatively large recoverable strain and insensitivity of MT temperatures to the copper content (Morgiel et al. 2002). It has also been shown that TiNiCu alloys obtained by crystallization from amorphous state possess the best performance. Amorphization of the alloys is achieved at high copper contents (above 20 at.\%) by means of rapid cooling at rates of about $10^{6} \mathrm{~K} / \mathrm{s}$ (Kang et al. 2010; Shelyakov et al. 2011; Senkovskiy et al. 2012) which can be implemented using the currently most widely applied amorphous metallic alloy technology of melt spinning onto the outer surface of a rapidly rotating wheel (Morgiel et al. 2002; Shelyakov et al. 2011; Pushin et al. 1997; Shelyakov, Matveeva, and Larin 1999). It has been recently shown that an increase in the copper content in melt-spun alloys to 38 at.\% has a considerable effect on their structural properties and performance (Sitnikov et al. 2017; Shelyakov et al. 2019; Sitnikov et al. 2018).

It should be noted that the melt spinning technique is suitable for the fabrication of up to 4 $\mathrm{mm}$ wide ribbons. However, since practical application often require up to $10 \mathrm{~mm}$ wide ribbons, the planar flow casting technique has been developed whose basic difference from the standard spinning technique is the slot shape of the nozzle (Kalin et al. 1996). Structure formation in rapidly quenched planar flow cast TiNiCu alloys with a copper content of above 25 at.\% during crystallization in a calorimeter was studied in earlier works (Sitnikov et al. 2017; Shelyakov et al. 2020a). In this work we dwelt upon the shape memory behavior in these alloys depending on the copper content and the method and duration of crystallization from amorphous state.

\section{Materials and Methods}

Quasibinary TiNi-TiCu alloys with copper contents of 25, 30, 35 and 40 at.\% were produced by the planar flow casting technique at a melt cooling rate of $10^{6} \mathrm{~K} / \mathrm{s}$ in the form of $30-50 \mu \mathrm{m}$ thick and 10-20 mm wide ribbons (Shelyakov et al. 2020a). A study of their structure showed that the as-cast alloys containing 25 and 30 at.\% Cu have an amorphous-crystalline structure with a thin $(1.5-3.5 \mu \mathrm{m})$ crystalline layer on the ribbon surfaces (Figure 1(a)) having the structure of the austenite phase $B 2$ whereas at copper contents of 35 and 40 at.\% the alloys are almost fully amorphous.

To obtain completely amorphous ribbons, so as to eliminate the effect of the crystalline layer on the test results, and to smooth their surface we electrochemically polished the alloys with thiourea electrolyte PLS/3 from NTP Technocom AS at $5 \mathrm{~V}$ for 20 min. Cross-section imaging of the as-electrochemically polished ribbons showed that there is no crystalline layer and the ribbon has a sufficiently uniform shape in section (Figure $1(b)$ ).
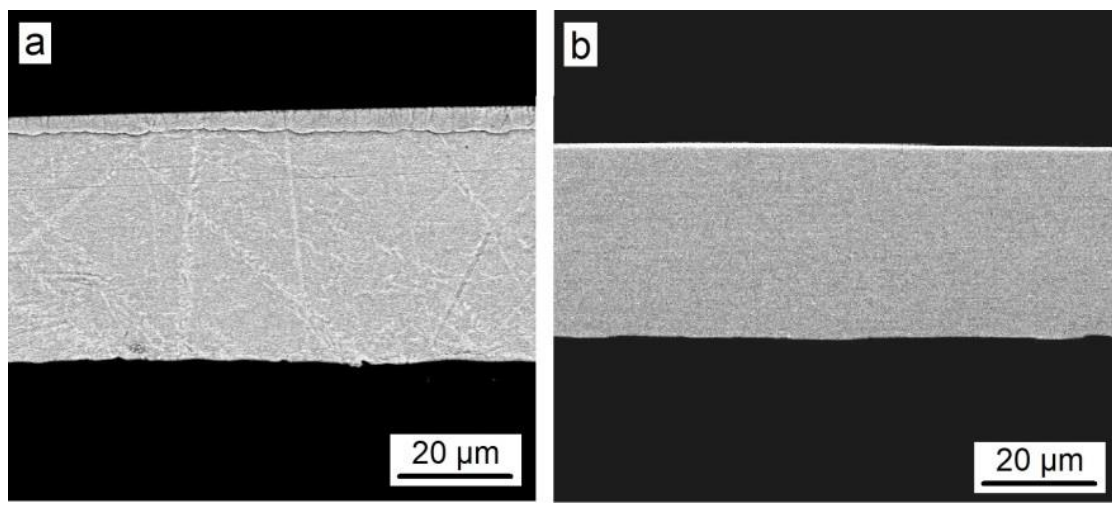

Figure 1: SEM cross-section images of rapidly quenched ribbon of TiNiCu alloy containing 25 at.\% Cu (a) as-quenched and (b) as-electrochemically polished 
The microstructure of the ribbon cross-sections was studied using a FEI Quanta 600 FEG scanning electron microscope (SEM).

The alloys were heat treated in two ways: by air isothermal annealing at $500^{\circ} \mathrm{C}$ for $100-300 \mathrm{~s}$ and by passing a short (10 ms duration) electric current pulse through the specimen. The annealing temperature was chosen based on earlier data (Shelyakov et al. 2020a), and the current amplitude and pulse duration were selected in accordance with an earlier described method (Shelyakov et al. 2011).

X-ray phase analysis was carried out on a PANalytical Empyrean diffractometer in $\mathrm{Cu} \mathrm{K}_{\alpha}$ radiation with Bragg-Brentano focusing and a hybrid monochromator. The fine structure of the alloys was studied under a JEOL JEM 2100 high resolution transmission electron microscope (TEM).

The thermomechanical properties and the shape memory effect (SME) parameters of the alloys were studied by means of bending tests (Shelyakov et al. 2020b) as schematically shown in Figure 2. A ribbon specimen with thickness $d$ having a preset straight shape memory was bent by $180^{\circ}$ in the martensitic state and placed between a stable and a movable pressure plates. The distance $D$ between the plates was set so the ribbon acquire the preset initial strain $\xi_{i}=d / D$ providing for the maximum specimen surface strain (position 1 in Figure 2). After the removal of the load and subsequent heating to above the reverse MT finish temperature $A_{f}$ the SME occurred in the specimen to recover the preset straight shape, either completely or partially (Figure 2, position 2), thus returning part $\xi_{\text {sme }}$ of the accumulated strain $\xi_{i}$ which characterizes the SME magnitude. As shown earlier (Shelyakov et al. 2020b), $\xi_{\text {sme }}$ is determined by the relationship $\xi_{s m e}=\xi_{i \cdot}\left(180^{\circ}-\alpha\right) / 180^{\circ}$, where the angle $\alpha$ is in degrees.

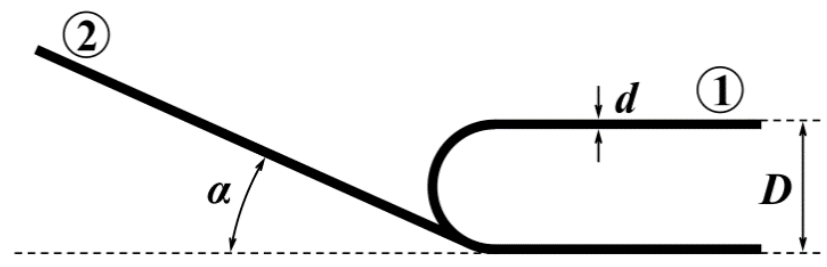

Figure 2: Schematic of bending test for evaluation of strain recovered by SME

The changes in the specimen shape and the angle $\alpha$ were traced using a special video control system and data processing software.

\section{Discussion}

X-ray diffraction analysis confirmed that the as-quenched and electrochemically polished alloys were amorphous (Figure 3 ). The diffraction patterns for the contact side (facing the quenching wheel) and for the non-contact side (free) of all the ribbons exhibit a smeared halo near $2 \theta=42$ deg without any structural peaks (Figure 3(a)). TEM study of the fine structure of the ribbons showed ultrafine absorption contrast typical of the amorphous phase in all the alloy specimens. A typical bright-field TEM image and the respective electron diffraction pattern for the alloy containing 30 at.\% $\mathrm{Cu}$ is shown in Figure 3(b). The diffraction patterns exhibit a number of diffuse rings with their intensity decreasing with an increase in the diffraction vector angle. 

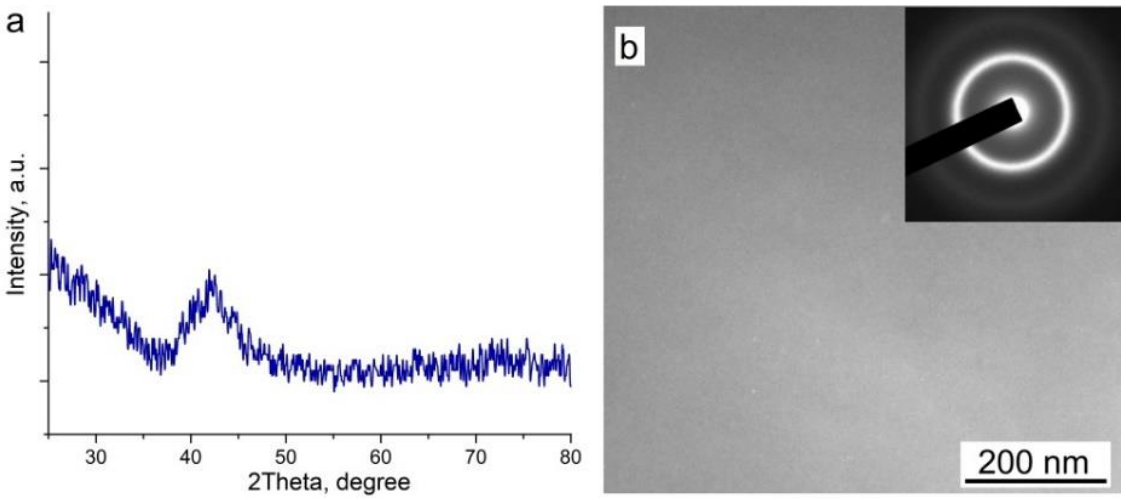

Figure 3: (a) X-ray diffraction pattern and (b) bright-field TEM image with the corresponding electron diffraction pattern (SAED) for the TiNiCu alloy with 30 at.\% Cu

Then the alloy specimens were exposed to crystallization annealing in isothermal and electropulse modes. The ribbon was preset to have a straight shape memory. Crystallization heat treatment is known to play a determinant role in the formation of the martensitic structure in amorphous TiNiCu alloys which in turn largely predetermines the martensitic transformations and the respective shape memory effects in these alloys.

Each of the alloys was tested for the thermomechanical properties for four specimens exposed to isothermal crystallization for 100, 200 and $300 \mathrm{~s}$ and dynamic crystallization with a $10 \mathrm{~ms}$ electric current pulse.

First of all we determined the maximum strain $\xi_{f}$, at which the ribbons were fractured for each of the specimens, by means of bending tests (Figure 4). The test data suggest that after isothermal heat treatment for $100 \mathrm{~s}$, an increase in the copper content leads to abrupt embrittlement of the alloys. The maximum strain $\xi_{f}$ of the alloy containing 30 at.\% copper after heat treatment in this mode was about $10 \%$, while in the alloy with 35 at.\% $\mathrm{Cu}$ it decreased to $3 \%$. Increasing the duration of isothermal heat treatment to 300 s reduced $\xi_{f}$ by a few percent. It should be noted that regardless of isothermal heat treatment duration the alloy containing 40 at.\% Cu fractured at $\xi_{f}<0.2 \%$ and hence is not capable of the SME. Rapid electropulse crystallization increased the plasticity of all the alloys, with the increase in $\xi_{f}$ being the greatest for the alloys containing 35 and 40 at.\% Cu. For example, the dynamically crystallized alloy with 40 at.\% copper can withstand strain to fracture of up to $4 \%$ and shows noticeable SME as will be shown later.

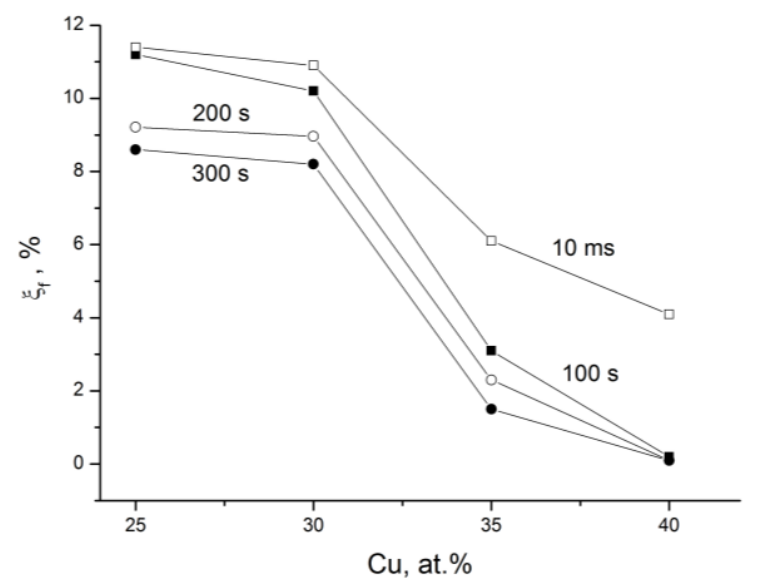

Figure 4: Bending fracture strain as a function of copper content and crystallization method and duration for rapidly quenched TiNiCu alloys

Then we evaluated the SME parameters for the alloys by measuring the SME-recovered strain $\xi_{\text {sme }}$ as a function of the initial strain $\xi_{j}$. The results suggest that $\xi_{\text {sme }}$ for the specimens 
containing 25 and 30 at.\% $\mathrm{Cu}$ increased almost linearly with the strain $\xi_{i}$ that indicates the complete recover of the preset straight shape due to the SME (Figures 5(a) and 5(b)). However at $\xi_{i}$ of above $3-5 \%$ the growth becomes considerably slower which seems to be caused by the exceeding of the pseudoplastic strain for the TiNi-TiCu system alloys (Shelyakov, Matveeva, and Larin 1999) and the generation of a tangible plastic strain. Importantly, a decrease in the isothermal heat treatment duration from 300 to $100 \mathrm{~s}$ leads to an increase in $\xi_{\text {sme }}$ at a constant $\xi_{i}$. The increase is the greatest for the maximum $\xi_{\text {sme }}$ which grows from 4.4 до $5.5 \%$ for the alloy containing 30 at.\% $\mathrm{Cu}$. An increase in the copper content significantly reduces the maximum $\xi_{\text {sme }}$ (Figures 5(c) and 6(a)), the alloy with 40 at.\% copper being so brittle that no SME occurs in it.
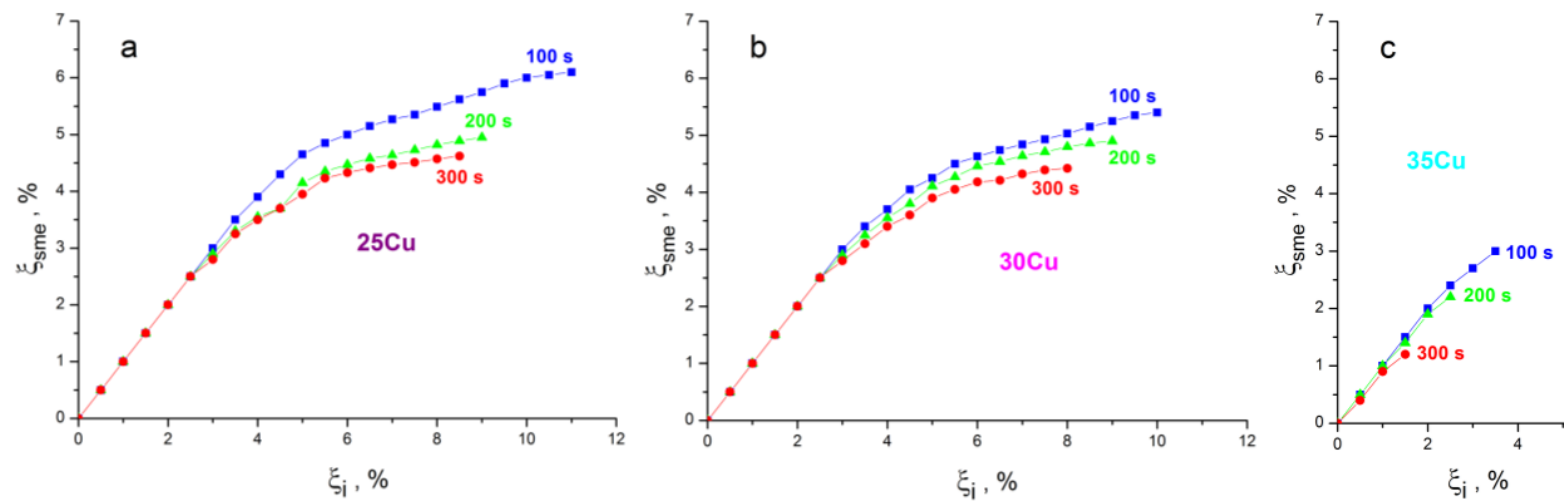

Figure 5: SME-recovered strain $\xi_{\text {sme }}$ as a function of initial strain $\xi_{i}$ for TiNiCu alloys containing (a) 25 , (b) 30 and (c) 35 at.\% Cu after isothermal heat treatment with different durations (100 s, $200 \mathrm{~s}$ and $300 \mathrm{~s})$

The thermomechanical parameters of the specimens with copper contents of 25 and 30 at.\% after dynamic electric pulse crystallization for $10 \mathrm{~ms}$ exhibit similar behavior and trends to those of the same specimens after isothermal heat treatment (Figure 6(b)). However the maximum strain $\xi_{\text {sme }}$ increases noticeably (from $6.1 \%$ to $6.9 \%$ for 25 at.\% $\mathrm{Cu}$ and from $5.4 \%$ to $6.6 \%$ for 30 at.\% $\mathrm{Cu}$ ). In the meantime dynamic crystallization of the specimens with high copper contents (35 and 40 at.\%) dramatically alters their thermomechanical properties. The alloy with 35 at.\% Cu exhibits an abrupt increase in the plasticity and the maximum strain $\xi_{\text {sme, }}$ whereas the alloy containing 40 at.\% $\mathrm{Cu}$, which undergoes embrittlement and shows no SME after isothermal heat treatment, shows significant SME after dynamic crystallization. The SME-recovered strain $\xi_{\text {sme }}$ increases permanently until fracture, the alloy being capable of relatively high strains until fracture.
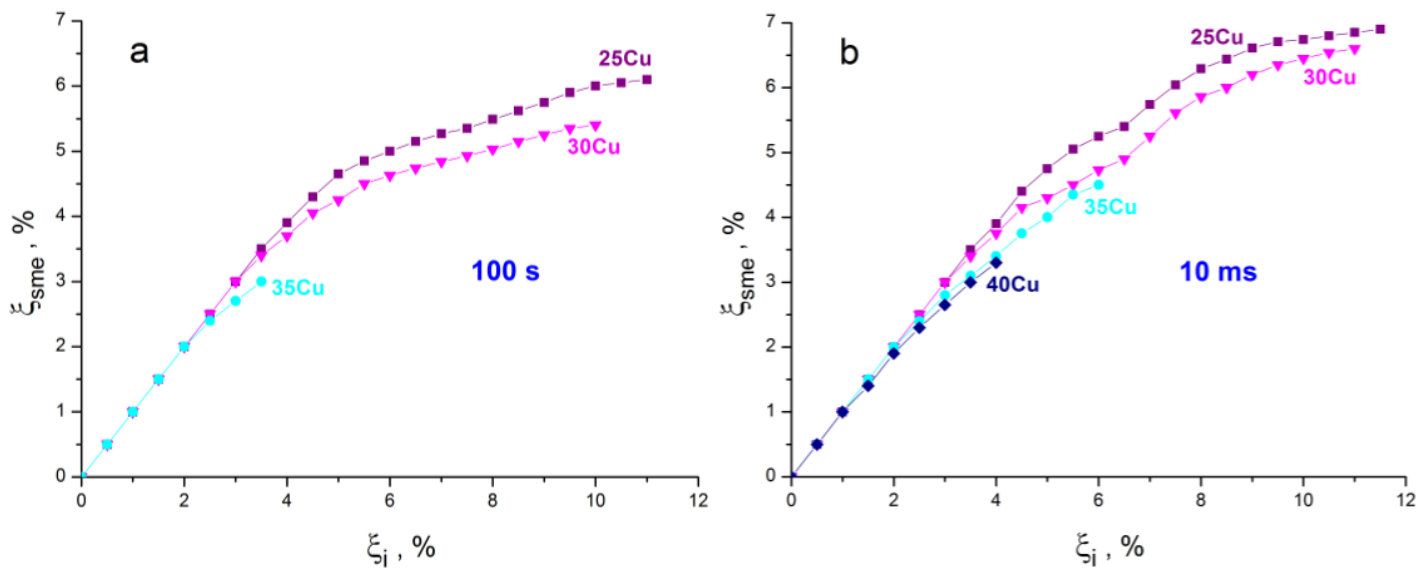

Figure 6: SME-recovered strain $\xi_{\text {sme }}$ as a function of initial strain $\xi_{i}$ for TiNiCu alloys with different copper contents after (a) isothermal crystallization for $100 \mathrm{~s}$ and (b) dynamic crystallization for $10 \mathrm{~ms}$ 
To reveal the origin of the shape memory behavior observed in the experiments we studied the as-crystallized alloys with X-ray diffraction. The SME in the TiNi-TiCu system alloys is known to originate from the thermoelastic MT $B 2 \leftrightarrow B 19$ giving rise to shape memory effect (Kang et al. 2010; Chang, Wu, and Kimura 2007; Morgiel et al. 2002; Shelyakov et al. 2011; Pushin et al. 1997; Shelyakov, Matveeva, and Larin 1999). It was shown earlier that standard isothermal heat treatment at $500^{\circ} \mathrm{C}$ for $300 \mathrm{~s}$ of amorphous TiNiCu alloys containing 20-25 at,\% copper produces a crystalline structure with the austenite phase $B 2$ ( $\mathrm{CsCl}$-type bcc lattice) which transforms to the martensite phase $B 19$ (Au-type orthorhombic lattice) upon cooling thus providing for the optimum SME performance (Chang, Wu, and Kimura 2007; Shelyakov, Matveeva, and Larin 1999). In this work we showed that the alloys containing 25 and 30 at.\% $\mathrm{Cu}$ after isothermal heat treatment for $300 \mathrm{~s}$ transit to the martensitic state with the B19 structure as illustrated by typical X- ray diffraction patterns in Figure 7(a). Decreasing the duration of isothermal crystallization from 300 to $100 \mathrm{~s}$ does not incur any visible changes in the X-ray diffraction patterns. Obviously it is structural behavior that accounts for the high SME in these alloys.

The alloy containing 35 at.\% Cu after isothermal heat treatment for $300 \mathrm{~s}$ has predominantly a B11 type structure (Figure 7(b)) which embrittles the alloy resulting in the absence of the SME. Decreasing the crystallization duration to $100 \mathrm{~s}$ significantly decreases the intensity of the $B 11$ phase peaks and $B 19$ phase reflexes emerge, i.e., a two-phase structure forms ( $B 19$ and $B 11$ ). As a result the alloys possesses the SME, though quite a little (Figure 5(c)).
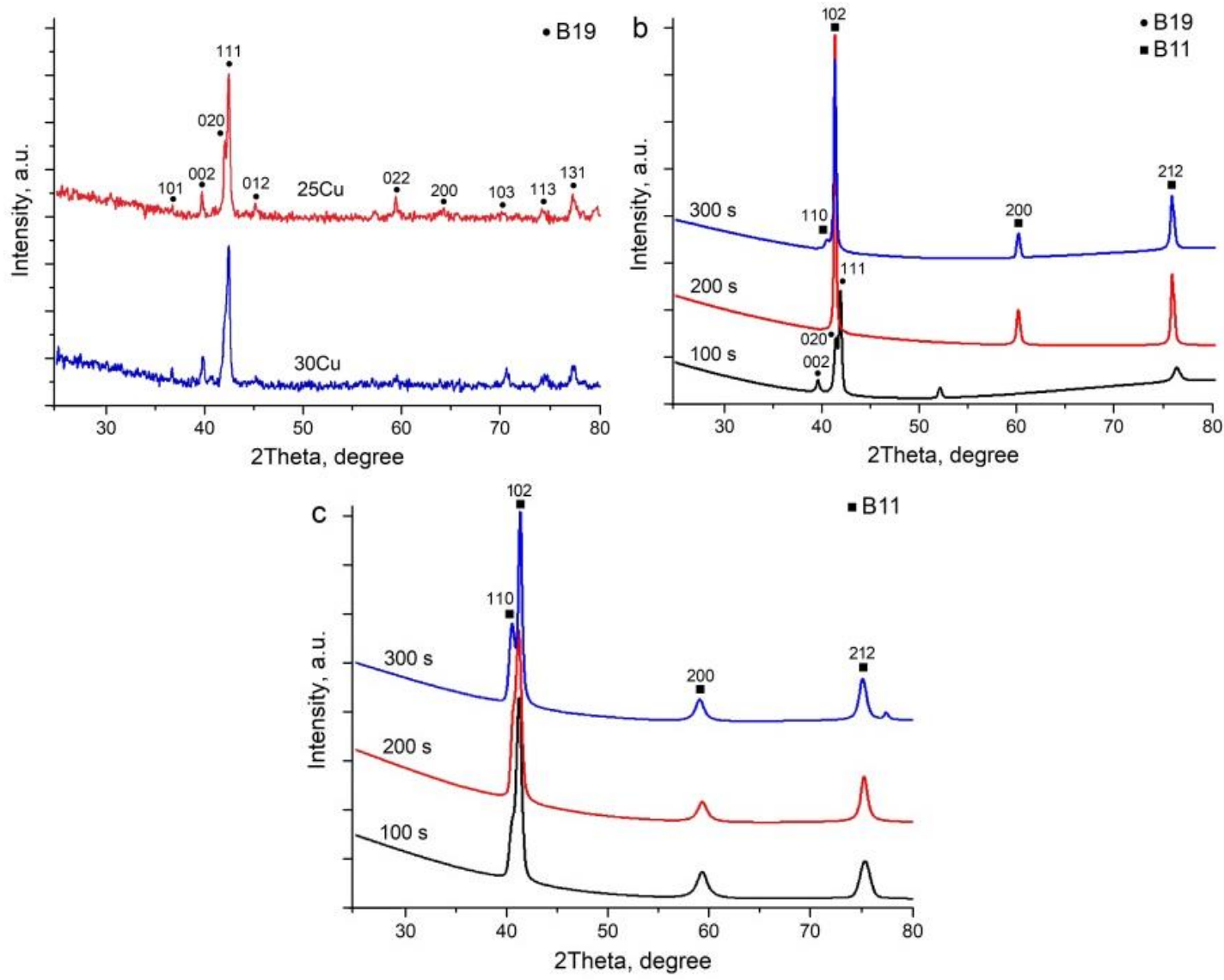

Figure 7: X- ray diffraction patterns of TiNiCu alloys after isothermal crystallization:

(a) 25 and 30 at.\% Cu for 300 s, (b) 35 at.\% Cu and (c) 40 at.\% Cu with different durations (100 s, $200 \mathrm{~s}$ and $300 \mathrm{~s}$ )

The alloy containing 40 at.\% Cu by analogy with the one containing 35 at.\% Cu after exposure for $300 \mathrm{~s}$ shows only the $B 11$ phase peaks in the X-ray diffraction pattern (Figure $7(c)$ ). 
Decreasing the heat treatment duration to $100 \mathrm{~s}$ changes only slightly the X-ray diffraction pattern but unlike the alloy containing 35 at.\% $\mathrm{Cu}$ all the $B 11$ phase peaks remain and no phase $B 19$ reflections emerge. Thus the structural state of the alloy containing 40 at.\% $\mathrm{Cu}$ after isothermal heat treatment with any duration is the brittle B11 phase accounting for the extremely low plasticity and the absence of the SME in this alloy.

High-rate electropulse crystallization changes the microstructure of the alloys containing 35 and 40 at.\% $\mathrm{Cu}$ in a fundamental manner in comparison with isothermal heat treatment. The main difference is that these alloys are almost completely martensitic with the $B 19$ structure at room temperature as confirmed by the presence of the $B 19$ phase reflections in the X-ray diffraction patterns and the absence of any pronounced peaks of brittle $B 11$ phase (Figure 8 ). Heating of the alloy containing 40 at. $\% \mathrm{Cu}$ to $75^{\circ} \mathrm{C}$ (above $A_{f}$ ) eliminated the $B 19$ phase peaks and only $B 2$ phase reflections remained, i.e., the alloy transited to the completely austenitic state as a result of $\mathrm{MT} B 19 \leftrightarrow B 2$. Thus electropulse heat treatment almost completely precludes the formation of the Ti-Cu phases in the alloys where the copper contents are above the limit copper solubility in TiNi ( 30 at.\%). This allowed attaining noticeable SME in these alloys.

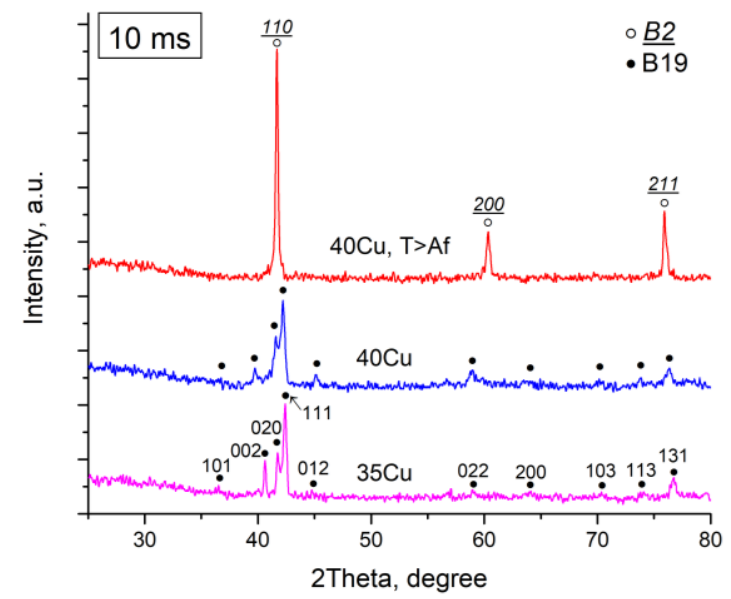

Figure 8: X-ray diffraction pattern of the TiNiCu alloys containing 35 and 40 at.\% $\mathrm{Cu}$ after electropulse crystallization for $10 \mathrm{~ms}$

The experimental data of this work are in a good agreement with earlier results for the TiNiTiCu system alloys with a high copper content produced by the melt spinning technique (Chang, Wu, and Kimura 2007; Morgiel et al. 2002; Shelyakov, Matveeva, and Larin 1999; Shelyakov et al. 2019; Sitnikov et al. 2018).

\section{Conclusions}

Amorphous ribbons of quasibinary TiNi-TiCu system alloys containing 25 to 40 at.\% copper were obtained by rapid quenching from the melt (the planar flow casting technique) followed by electrochemical polishing. The alloys specimens were exposed to isothermal crystallization at $500{ }^{\circ} \mathrm{C}$ with variable exposure duration of 300 to $100 \mathrm{~s}$ and electropulse heat treatment for $10 \mathrm{~ms}$.

Thermomechanical bending tests showed that an increase in the copper content in the isothermally crystallized specimens to above 30 at.\% caused an abrupt decrease in the plasticity of the alloys and elimination of the SME in the alloy containing 40 at.\% $\mathrm{Cu}$. This was shown to originate from the formation of brittle Ti-Cu phases in the structure of the alloys. Decreasing the heat treatment duration from 300 to $100 \mathrm{~s}$ produced minor changes in the structure of the alloys accompanied by a slight increase in their plasticity and SME magnitude. 
The use of dynamic crystallization with short electric current pulses provides significantly shorter crystallization durations thus precluding the formation of brittle Ti-Cu phases in highcopper TiNi-TiCu system alloys where the copper contents are above the limit copper solubility in TiNi ( 30 at.\%) thus providing for pronounced SME in these alloys.

\section{References}

Chang, S. H., S. K. Wu, and H. Kimura. 2007. "Annealing effects on the crystallization and shape memory effect of Ti50Ni25Cu25 melt-spun ribbons". Intermetallics 15, no. 3: 233-40. https://doi.org/10.1016/j.intermet.2006.05.014.

Kalin, B. A., V. T. Fedotov, O. N. Sevryukov, and A. E. Grigoriev. 1996. "Amorphous ribbon solder for high temperature brazing. Experience in the development of production technology and application". Svaroch. Pr-vo 1: 15-19.

Kang, S. W., Y. M. Lim, Y. H. Lee, H. J. Moon, Y. W. Kim, and T. H. Nam. 2010. "Microstructures and shape memory characteristics of a Ti-20Ni-30Cu (at.\%) alloy strip fabricated by the melt overflow process". Scripta Materialia 62, no. 2: 71-74. https://doi.org/10.1016/j.scriptamat.2009.09.034.

Kohl, M., H. Ossmer, M. Gueltig, and C. Megnin. 2018. "SMA foils for MEMS: From material properties to the engineering of microdevices". Shape Memory and Superelasticity 4, no. 1: 127-42. https://doi.org/10.1007/s40830-017-0144-x.

Mohd Jani, J., M. Leary, A. Subic, and M. A. Gibson. 2014. "A review of shape memory alloy research, applications and opportunities". Materials \& Design 56: 1078-113. https://doi.org/10.1016/j.matdes.2013.11.084.

Morgiel, J., E. Cesari, J. Pons, A. Pasko, and J. Dutkiewicz. 2002. "Microstructure and martensite transformation in aged Ti-25Ni-25Cu shape memory melt spun ribbons". Journal of Materials Science 37, no. 24: 5319-25. https://doi.org/10.1023/A:1021077025254.

Nam, T. H., T. Saburi, and K. Shimizu. 1990. "Cu-content dependence of shape memory characteristics in Ti-Ni-Cu alloys". Materials Transactions, JIM 31, no. 11: 959-67. https://doi.org/10.2320/matertrans1989.31.959.

Nespoli, A., S. Besseghini, S. Pittaccio, E. Villa, and S. Viscuso. 2010. "The high potential of shape memory alloys in developing miniature mechanical devices: A review on shape memory alloy mini-actuators". Sensors and Actuators, A: Physical 158, no. 1: 149-60. https://doi.org/10.1016/j.sna.2009.12.020.

Otsuka, K., and X. Ren. 2005. "Physical metallurgy of Ti-Ni-based shape memory alloys". Progress in Materials Science 50, no. 5: 511-678. https://doi.org10.1016/j.pmatsci.2004.10.001.

Pushin, V. G., S. B. Volkova, N. M. Matveeva, L. I. Yurchenko, and A. S. Chistyakov. 1997. "Structural and phase transformations in quasi-binary TiNi-TiCu alloys rapidly quenched from the melt: IV. The microstructure of crystalline alloys". Physics of Metals and Metallography 83, no. 6: 673-78.

Senkovskiy, B. V., D. Y. Usachov, A. V. Fedorov, O. Y. Vilkov, A. V. Shelyakov, and V. K. Adamchuk. 2012. "Electronic structure of Ti-Ni alloys: An XPS and NEXAFS study". Journal of Alloys and Compounds 537: 190-96. https://doi.org/10.1016/j.jallcom.2012.05.059.

Shelyakov, A., N. Sitnikov, I. Khabibullina, N. Tabachkova, V. Fominski, and N. Andreev. 2019. "Effect of high-rate annealing on microstructure, martensitic transformation and shape 
memory behavior of TiNiCu melt-spun ribbons". Materials Letters 248: 48-51. https://doi.org/10.1016/j.matlet.2019.03.140.

Shelyakov, A. V., N. N. Sitnikov, I. A. Khabibullina, R. V. Sundeev, and O. N. Sevryukov. 2020a. "Specifics of crystallization of amorphous TiNiCu alloys with high concentrations of copper". Physics of the Solid State 62, no. 6: 937-41. https://doi.org/10.1134/S1063783420060281.

Shelyakov, A. V., N. N. Sitnikov, K. A. Borodako, and O. N. Sevryukov. 2020b. "Two-way shape memory effect in rapidly-quenched high-copper TiNiCu alloys deformed in the martensitic state". Russian Metallurgy 2020, no. 4: 345-50. https://doi.org/10.1134/S0036029520040278.

Shelyakov, A. V., N. N. Sitnikov, A. P. Menushenkov, V. V. Koledov, and A. I. Irjak. 2011. "Nanostructured thin ribbons of a shape memory TiNiCu alloy". Thin Solid Films 519, no. 15: 5314-17. https://doi.org/10.1016/j.tsf.2011.01.118.

Shelyakov, A. V., N. M. Matveeva, and S. G. Larin. 1999. "Rapidly quenched TiNi-based shape memory alloys". In Shape memory alloys: Fundamentals, modeling and industrial applications, International Symposium, 1999, edited by F. Trochu, V. Brailovski and A. Galibois, 295-303. Montreal: Canadian Inst. Mining, Metallurgy and Petroleum.

Sitnikov, N., A. Shelyakov, R. Rizakhanov, N. Mitina, and I. Khabibullina. 2017. "The effect of copper on structure of TiNiCu melt-spun ribbons". Materials Today: Proceedings 4, no. 3: 4680-84. https://doi.org/10.1016/j.matpr.2017.04.051.

Sitnikov, N., A. Shelyakov, I. A. Khabibullina, and N. Mitina. 2018. "Effect of the conditions of crystallization of rapidly quenched TiNiCu amorphous alloys with high copper contents on the characteristics of martensite transformations and shape memory effect". Bulletin of the Russian Academy of Sciences: Physics 82, no. 9: 1106-12. https://doi.org/10.3103/S1062873818090216.

\section{Acknowledgments}

This study was supported by the Russian Science Foundation (project no. 19-12-00327). 